\title{
RELAXATION OF EXCITED Eu(III) COMPLEXES IN CETYLTRIMETHYLAMMONIUM BROMIDE MICELLAR SOLUTIONS
}

\author{
C.A. Sennoga and C.D. Flint* \\ Laser Laboratory, Department of Chemistry \\ Birkbeck College, University of London \\ Gordon House, 29 Gordon Square, London WC1H 0PP, United Kingdom
}

The equilibria between pyridine-2,6-dicarboxylate and $\mathrm{Eu}(\mathrm{III})$ in $\mathrm{H}_{2} \mathrm{O}$ or $\mathrm{D}_{2} \mathrm{O}$ cetyltrimethylammonium bromide micellar solutions at room temperature have been made as a function of the ligand concentration and $\mathrm{pH}$ by excitation spectroscopy and emission decay measurements. Formation of the tris-complex is complete at $\left[\mathrm{Eu}^{3+}\right]:\left[\mathrm{pdc}^{2-}\right] \geq 1: 4$ at neutral to slightly alkaline conditions but is incomplete under acidic conditions. The ${ }^{5} D_{0}$ lifetimes corresponding to the $\mathrm{Eu}(\mathrm{pdc})_{3}^{3-}$ anion is observed to increase on association of the complex with the micellar surface due to exclusion of the solvating molecules from the second co-ordination sphere. Energy transfer in the bulk solution requires the presence of binuclear mixed $\mathrm{Eu}^{3+}$ and $\mathrm{Nd}(\mathrm{pdc})_{3}^{3-}$ complexes or confinement of the $\mathrm{Ln}(\mathrm{pdc})_{3}^{3-} / \mathrm{Eu}^{3+}$ on the micelle surface. Energy transfer from the $\mathrm{Eu}(\mathrm{pdc})_{3}^{3-}$ anion is inefficient in the bulk solution.

PACS numbers: $33.50 . \mathrm{Dq}, 82.20 . \mathrm{Rp}$

\section{Introduction}

The luminescence properties of $\mathrm{Ln}^{3+}$ complexes, especially those of $\mathrm{Eu}^{3+}$, $\mathrm{Tb}^{3+}$ and $\mathrm{Sm}^{3+}$ are of interest because of their applications as structural probes in chemical and biomedical diagnostics. In previous contributions [1-3], we have shown that, at $\mathrm{pII}=7$, complex formation between $\mathrm{Eu}^{3+}$ and pyridine-2,6-dicarboxylate $(\mathrm{pdc})$ is essentially complete at $\left[\mathrm{Eu}^{3+}\right]:\left[\mathrm{pdc}^{2-}\right]$ molar ratios of $1: 3.5$ but not at 1:3.0.

Association of the $\mathrm{Eu}(\mathrm{pdc})_{3}^{3-}$ anion with the cationic micellar surface of the cetyltrimethylammonium (CTA) cation results in a decrease in the observed decay rate. This decrease is the result of a small increase in the radiative decay rate due to distortion of the complex and a larger decrease in the non-radiative decay rate due to the exclusion of water molecules from the outer co-ordination spheres of the

\footnotetext{
*To whom all correspondences should be addressed.
} 
europium complex. Energy transfer between the $\mathrm{Eu}(\mathrm{pdc})_{3}^{3-}$ anion and $\operatorname{Ln}(\mathrm{pdc})_{3}^{3-}$ ( $\mathrm{Ln}=\mathrm{Nd}, \mathrm{Pr}, \mathrm{Sm}, \mathrm{Ho}, \mathrm{Er}$ ) occurs in the bulk solution.

In this paper we extend all the above studies to examine the structural and chemical changes as a function of pII.

\section{Experimental}

All experimental data were obtained following similar methods as previously described [1].

\section{Results}

Figure 1 shows the ${ }^{7} F_{0} \rightarrow{ }^{5} D_{0}$ excitation spectra of solutions containing $\left[\mathrm{Eu}^{3+}\right]=4 \times 10^{-3} \mathrm{~mol} \mathrm{dm}{ }^{3}$ with different pdc molar ratios $R=\left[\mathrm{pdc}^{2-}\right] /\left[\mathrm{Eu}^{3+}\right]$ at $298 \mathrm{~K}$ in the region 17150-17350 wave numbers $\mathrm{cm}^{-1}$ as a function of pII. For brevity, pII $=3,7$ and 10 are shown. In this spectral region the only transition present is between non-degenerate states so that each transition maximum corresponds to a different chemical species. Under identical excitation conditions the intensity of a line is proportional to the concentration of that species, but for the different lines it depends on the radiative and non-radiative transition probabilities of the different chemical species. Formation of partly complexed species such as $\mathrm{Eu}(\mathrm{pdc})_{2}\left(\mathrm{OH}_{2}\right)_{3}^{-}$will result in an increase in the radiative rate due to the distortion of the co-ordination sphere and an increase in the non-radiative rate due to the presence of water molecules whose high frequency vibrations have a substantial dipole. Each of the emission bands has a distinct lifetime so that chemical interconversions are not fast on the time scale of the luminescence lifetimes. IIowever, the dependence of the decay constants on the ratio $R$ shows that chemical interconversions do occur with a rate comparable to the decay constants.

Tables I and II show the corresponding ${ }^{5} D_{0}$ decay constants and the excitation intensities of these transitions. The excitation maxima are independent of pII. The pII dependence of the decay constant of a given species and its dependence on the bulk pdc/Eu ratio $(R)$ is then due to chemical equilibria involving that species. In acidic media, pdc anions are removed from solution through protonation of the carboxylate groups and the protonated species do not contribute to formation constant of the europium complexes. Of course, the removal of free pdc anions from the bulk solution due to complex formation with $\mathrm{Eu}^{3+}$ will effect these equilibria.

The $17241 \mathrm{~cm}^{-1}$ maximum is clearly due to the species $\mathrm{Eu}(\mathrm{pdc})_{3}^{3-}$ since addition of large quantities of pdc causes no spectral change at any pII. It is reasonable to associate the 17262 and $17277 \mathrm{~cm}^{-1}$ maxima with the species $\mathrm{Eu}(\mathrm{pdc})_{2}\left(\mathrm{OH}_{2}\right)_{3}^{-}$and $\mathrm{Eu}(\mathrm{pdc})\left(\mathrm{OH}_{2}\right)_{6}^{+}$respectively. The co-ordinated water molecules are likely to be partly deprotonated at the pII values used in this study. At $\mathrm{pII}=7$ and $\mathrm{pH}=10 \mathrm{in}$ the presence of excess pdc, the excitation spectra consist of a single peak with a decay constant of $610 \mathrm{~s}^{-1}$. At acidic pII complex formation is not complete at $R=4$ but is essentially complete at $R=5$. The decay constant is slightly faster at acidic pII. This might reflect some slight chemical interconversion to $\mathrm{Eu}(\mathrm{pdc})_{2}\left(\mathrm{OH}_{2}\right)_{3}^{-}$or more likely distortion of the complex due to partial protonation of the trinegative anion. For $\mathrm{pH}=10$ the decay constant of 


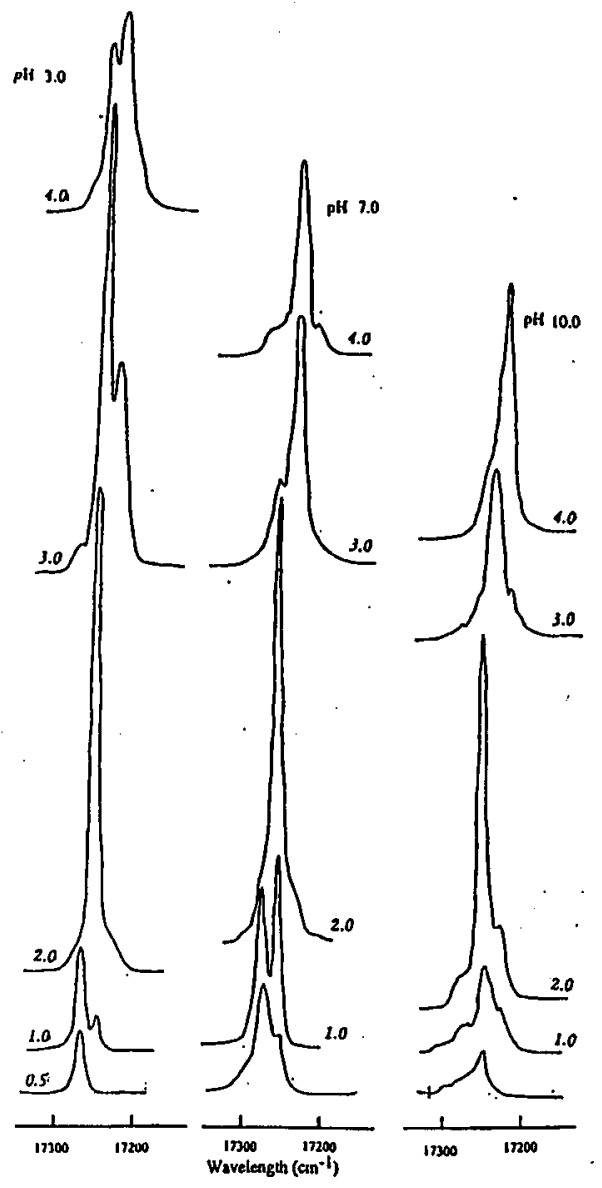

Fig. 1. The ${ }^{5} D_{0} \rightarrow{ }^{7} F_{0}$ excitation spectra of $\mathrm{Eu}^{3+}$ solutions containing $\left[\mathrm{Eu}^{3+}\right]=$ $4 \times 10^{-3} \mathrm{~mol} \mathrm{dm^{-3 }}$, with different [pdc ${ }^{2-}$ ] molar ratios at $\mathrm{pH}=3,7,10$ and $298 \mathrm{~K}$. Emissions were monitored at $614 \mathrm{~nm} . R=\left[\mathrm{pdc}^{2-}\right] /\left[\mathrm{Eu}^{3+}\right]$.

the tris species is independent of $R$ until $R<3$. At lower $R$ values it is difficult to measure the decay constant of the tris species due to its low abundance, it does appear however that the decay constant of the emission from this species increases when the concentration of the bis species is high. This would be consistent with an interconvertion of the tris and bis species on a time scale comparable to their emission lifetimes (i.e. with a rate constant of the order of 1000). Similar effects are observable at lower $\mathrm{pH}$.

The decay constant of the bis species at $\mathrm{pH}=7$ or $\mathrm{pH}=10$ is $1730 \mathrm{~s}^{-1}$. This increases slightly as $R$ decreases. Again we attribute this to equilibria between the bis and the mono species, the change in the decay constant is not large however due in part to the fact that the decay constant of the mono species is only slightly faster than that of the bis complex. 
TABLE I

The ${ }^{5} D_{0}$ decay rate constants $\left(k \times 10^{2}\right) \mathrm{s}^{-1}$ of $\mathrm{Eu}(\mathrm{pdc})\left(\mathrm{OH}_{2}\right)_{6}^{+}, \mathrm{Eu}(\mathrm{pdc})_{2}\left(\mathrm{OH}_{2}\right)_{3}^{-}$ and $\mathrm{Eu}(\mathrm{pdc})_{3}^{3-}$ (observed at 17277,17262 and $17241 \mathrm{~cm}^{-1}$, respectively), obtained from quantitative molar titration of $\left[\mathrm{Eu}^{3+}\right]=4 \times 10^{-3} \mathrm{~mol} \mathrm{dm}^{-3}$ with different [pdc ${ }^{2-}$ ] ratios as a function of $\mathrm{pH}$ variation in $\mathrm{H}_{2} \mathrm{O}$ and $\mathrm{D}_{2} \mathrm{O}$ at $298 \mathrm{~K}$. For brevity, only $\mathrm{pH}=3,7$ and 10 are shown: $\lambda_{\mathrm{ex}}=17300 \div 17200 \mathrm{~cm}^{-1} ; \lambda_{\mathrm{em}}=614 \mathrm{~nm}$ and $R=\mathrm{pdc}^{2-} / \mathrm{Eu}^{3+}$.

\begin{tabular}{c|c|c|c|c|c|c|c|c|c}
\hline \hline \multirow{2}{*}{$R$} & \multicolumn{3}{|c|}{$\mathrm{II}=3$} & \multicolumn{3}{c|}{$\mathrm{pI}=7$} & \multicolumn{3}{c}{$\mathrm{pI}=10$} \\
\cline { 2 - 9 } & $\begin{array}{l}17277 \\
\mathrm{~cm}^{-1}\end{array}$ & $\begin{array}{l}17262 \\
\mathrm{~cm}^{-1}\end{array}$ & $\begin{array}{l}17241 \\
\mathrm{~cm}^{-1}\end{array}$ & $\begin{array}{c}17277 \\
\mathrm{~cm}^{-1}\end{array}$ & $\begin{array}{l}17262 \\
\mathrm{~cm}^{-1}\end{array}$ & $\begin{array}{l}17241 \\
\mathrm{~cm}^{-1}\end{array}$ & $\begin{array}{l}17277 \\
\mathrm{~cm}^{-1}\end{array}$ & $\begin{array}{c}17262 \\
\mathrm{~cm}^{-1}\end{array}$ & $\begin{array}{c}17241 \\
\mathrm{~cm}^{-1}\end{array}$ \\
\hline 0.5 & 2.95 & & & 2.06 & 2.83 & & & & \\
1.0 & 2.72 & 2.54 & & 2.71 & 2.61 & & & & \\
2.0 & & 2.49 & 1.24 & & 2.20 & 1.05 & & 2.42 & 1.16 \\
3.0 & & 2.29 & 0.73 & & 1.73 & 0.69 & & 1.73 & 0.62 \\
4.0 & & 6.95 & 0.69 & & & 0.61 & & & 0.61 \\
5.0 & & & 0.68 & & & 0.61 & & & 0.61 \\
$(4.0)$ & & $(0.27)$ & $(0.28)$ & & & $(0.28)$ & & & $(0.27)$ \\
\hline
\end{tabular}

The bracketed values are the $\mathrm{D}_{2} \mathrm{O}$ decay rate constants.

TABLE II

The relative excitation intensities $(\mathrm{cm})$ of $\mathrm{Eu}(\mathrm{pdc})\left(\mathrm{OH}_{2}\right)_{6}^{+}, \mathrm{Eu}(\mathrm{pdc})_{2}\left(\mathrm{OH}_{2}\right)_{3}^{-}$and $\mathrm{Eu}(\mathrm{pdc})_{3}^{3-}$ (observed at 17277,17262 and $17241 \mathrm{~cm}^{-1}$, respectively), obtained from quantitative molar titration of $\left[\mathrm{Eu}^{3+}\right]=4 \times 10^{-3} \mathrm{~mol} \mathrm{dm}^{-3}$ with different [pdc ${ }^{2-}$ ] ratios as a function of $\mathrm{pH}$ variation in $\mathrm{H}_{2} \mathrm{O}$ and $\mathrm{D}_{2} \mathrm{O}$ at $298 \mathrm{~K}$. For brevity, only $\mathrm{pH}=3,7$ and 10 are shown: $\lambda_{\mathrm{ex}}=17300 \div 17200 \mathrm{~cm}^{-1} ; \lambda_{\mathrm{em}}=614 \mathrm{~nm}$ and $R=\operatorname{pdc}^{2-} / \mathrm{Eu}^{3+}$.

\begin{tabular}{c|c|c|c|c|c|c|c|c|c}
\hline \hline & \multicolumn{3}{|c|}{$\mathrm{pII}=3$} & \multicolumn{3}{c|}{$\mathrm{pII}=7$} & \multicolumn{3}{c}{$\mathrm{pH}=10$} \\
\cline { 2 - 9 }$R$ & $\begin{array}{c}17277 \\
\mathrm{~cm}^{-1}\end{array}$ & $\begin{array}{l}17262 \\
\mathrm{~cm}^{-1}\end{array}$ & $\begin{array}{c}17241 \\
\mathrm{~cm}^{-1}\end{array}$ & $\begin{array}{c}17277 \\
\mathrm{~cm}^{-1}\end{array}$ & $\begin{array}{c}17262 \\
\mathrm{~cm}^{-1}\end{array}$ & $\begin{array}{c}17241 \\
\mathrm{~cm}^{-1}\end{array}$ & $\begin{array}{c}17277 \\
\mathrm{~cm}^{-1}\end{array}$ & $\begin{array}{c}17262 \\
\mathrm{~cm}^{-1}\end{array}$ & $\begin{array}{c}17241 \\
\mathrm{~cm}^{-1}\end{array}$ \\
\hline 0.5 & 4.4 & & & 3.9 & 2.1 & & 1.5 & & \\
1.0 & 7.2 & 2.4 & & 5.6 & 6.7 & & & 2.9 & \\
2.0 & & 33.2 & 2.0 & & 16.3 & 1.7 & & 12.8 & 2.9 \\
3.0 & & 16.2 & 7.9 & & 3.0 & 8.1 & & 6.0 & 1.3 \\
4.0 & & 5.9 & 7.1 & & & 6.6 & & 8.0 & \\
5.0 & & & 6.8 & & & 6.0 & & &
\end{tabular}

A weak peak due to $\mathrm{Eu}(\mathrm{pdc})_{2}\left(\mathrm{OH}_{2}\right)_{3}^{-}$at $\mathrm{pII}=3$ which also has the characteristic decay constant of $695 \mathrm{~s}^{-1}$ is present at $\left[\mathrm{Eu}^{3+}\right]$ :[ $\left.\mathrm{pdc}^{2-}\right]$ molar ratios of $1: 4$ suggesting that under these acidic conditions, complex formation remains incomplete below molar ratios of 1:5.0. The lack of a simple correlation between observed 
intensities and the emissive lifetimes indicates the complexity of the equilibria involved.

The equilibria between $\mathrm{Eu}(\mathrm{pdc})_{3}^{3-}$ in bulk solution and on the surface of CTA micelles at pII $=7$ have been discussed previously [1]. For Eu:pdc ratios of $1: 4$, the results are entirely consistent with our previous studies (Table III). At higher pHs the results are essentially identical. Ilowever, for $\mathrm{pH} 4$ or lower a

TABLE III

The ${ }^{5} D_{0}$ decay rate constants $\left(k \times 10^{2}\right) \mathrm{s}^{-1}$ of $\mathrm{Eu}(\mathrm{pdc})_{3}^{3-} /$ CTA (observed at $17241 \mathrm{~cm}^{-1}$ obtained from quantitative molar titration of $\left[\mathrm{Eu}^{3+}\right]=4 \times 10^{-3} \mathrm{~mol} \mathrm{dm}^{-3}$ in Eu(pdc) ${ }_{3}^{3-}$ with varying [CTA] molar ratios as a function of $\mathrm{pH}$ variation in $\mathrm{H}_{2} \mathrm{O}$ at $298 \mathrm{~K}$. $\lambda_{\mathrm{ex}}=17300 \div$ $17200 \mathrm{~cm}^{-1} ; \lambda_{\mathrm{em}}=614 \mathrm{~nm}$.

\begin{tabular}{c|l|l|l|l|l|l|c}
\hline \hline \multicolumn{4}{c|}{$\mathrm{pH}$} & \multicolumn{4}{c}{$\mathrm{CTA}$} \\
\hline 0.0 & 0.1 & 2.0 & 3.0 & 2.0 & 4.0 & 8.0 & 12.0 \\
16.0 & 3.0 & 6.90 & 6.92 & 5.95 & 5.85 & 5.71 & 5.62 \\
5.60 & 5.61 & 5.55 & 4.0 & 6.80 & 6.25 & 5.97 & 5.86 \\
5.73 & 5.64 & 5.79 & 5.65 & 5.57 & 5.0 & 6.10 & 6.20 \\
6.10 & 5.88 & 5.74 & 5.64 & 5.81 & 5.68 & 5.57 & 6.0 \\
6.00 & 6.19 & 6.13 & 5.87 & 5.74 & 5.64 & 5.80 & 5.67 \\
5.57 & 7.0 & 6.10 & 6.19 & 6.11 & 6.04 & 5.76 & 5.65 \\
5.82 & 5.69 & 5.58 & 8.0 & 6.10 & 6.19 & 6.15 & 76.10 \\
5.80 & 5.71 & 5.88 & 5.73 & 5.64 & 9.0 & 6.20 & 6.20 \\
6.15 & 6.11 & 5.81 & 5.70 & 5.88 & 5.74 & 5.63 & 10.0 \\
6.10 & 6.19 & 6.12 & 6.09 & 5.77 & 5.66 & 5.87 & 5.70
\end{tabular}

measurable increase in the decay constant occurs for CTA concentrations below or only slightly above the critical micelle concentration. Under the conditions of this experiment, most of the $\mathrm{Eu}(\mathrm{pdc})_{3}^{3-}$ is present in the bulk solution until the mole ratio of $\mathrm{Eu}^{3+}$ to CTA is $\geq 1: 4$, thereafter almost all of the $\mathrm{Eu}(\mathrm{pdc})_{3}^{3-}$ are associated with the micellar surface. We conclude that at low pII the presence of the highly positively charged micellar surface stabilised the formation of the tris complex, i.e. it allects the equilibria between the bis and tris complexes to favour the latter.

Further information on these equilibria in solution may be obtained by the introduction of a quenching agent. We have used $\mathrm{Nd}^{3+}$ in dynamic equilibrium with the pdc anions. When pdc is in excess ( $p d c: \operatorname{Ln}>4$ ) the $\mathrm{Nd}^{3+}$ has no effect, the interaction between the $\mathrm{Eu}(\mathrm{pdc})_{3}^{3-}$ and the $\mathrm{Nd}(\mathrm{pdc})_{3}^{3-}$ being negligible at any pII. For pdc: $\mathrm{Ln}=4: 1$, i.e. when most of the lanthanide is present as the bis complex, the decay constants for the $\mathrm{Eu}^{3+}$ emission are much faster but only increase slightly with $\mathrm{pH}$. This is consistent with the formation of oxygen bridged 
binuclear species of the type

$\mathrm{OH}$

$$
(\mathrm{pdc})_{2} \mathrm{Eu} \quad \mathrm{Nd}(\mathrm{pdc})_{2} \text {. }
$$

$\mathrm{OH}$

It is possible to see emission from both $\mathrm{Eu}(\mathrm{pdc})_{3}^{3-}$ and $\mathrm{Eu}(\mathrm{pdc})_{2}\left(\mathrm{OH}_{2}\right)_{3}^{-}$in these solutions and both are similarly quenched. If as at higher pII and in the presence of excess pdc the interaction between the tris complexes is small, this implies that the rate of interconversion of these species is at least comparable to their decay constants. oxide.

Beyond $\mathrm{pH}=6.5$ the $\mathrm{Nd}^{3+}$ precipitates from solution as the hydrated hydr-

\section{Conclusions}

The ${ }^{5} D_{0} \rightarrow{ }^{7} F_{0}$ emission from $\mathrm{Eu}(\mathrm{pdc})_{n}\left(\mathrm{OII}_{2}\right)_{9-3 n}$ have been measured as a function of $\mathrm{pH}$ and in the presence of CTA micelles and $\mathrm{Nd}(\mathrm{pdc})_{n}\left(\mathrm{OII}_{2}\right)_{9-n}$ as a quenching agent. We conclude that the rate of interconversion of the Eu species is comparable to their luminescence decay rates and this leads to a variety of complex interdependences. The presence of cationic micelles stabilises the formation of the tris species.

\section{References}

[1] W. Dong, C.D. Plint, J. Chem. Soc. Faraday Trans. 88, 705 (1992).

[2] W. Dong, C.D. Flint, J. Chem. Soc. Faraday Trans. 88, 2661 (1992).

[3] W. Dong, C.D. Flint, Acta Phys. Pol. A 84, 985 (1993). 